\title{
Front Matter: Volume 11933
}

, "Front Matter: Volume 11933," Proc. SPIE 11933, 2021 International Conference on Neural Networks, Information and Communication Engineering, 1193301 (2 November 2021); doi: 10.1117/12.2616760

Event: 2021 International Conference on Neural Networks, Information and SPIE. Communication Engineering, 2021, Qingdao, China 


\section{PROCEEDINGS OF SPIE}

\section{International Conference on Neural Networks, Information and Communication Engineering}

Zhiyong Zhang

Editor

August 27-29, 2021

Qingdao, China

Organized by

Henan University of Science and Technology (China)

Sponsored by

AEIC Academic Exchange Information Centre (China)

Published by

SPIE 
The papers in this volume were part of the technical conference cited on the cover and title page. Papers were selected and subject to review by the editors and conference program committee. Some conference presentations may not be available for publication. Additional papers and presentation recordings may be available online in the SPIE Digital Library at SPIEDigitalLibrary.org.

The papers reflect the work and thoughts of the authors and are published herein as submitted. The publisher is not responsible for the validity of the information or for any outcomes resulting from reliance thereon.

Please use the following format to cite material from these proceedings:

Author(s), "Title of Paper," in 2021 International Conference on Neural Networks, Information and Communication Engineering, edited by Zhiyong Zhang, Proc. of SPIE 11933, Seven-digit Article CID Number (DD/MM/YYYY); (DOI URL).

ISSN: 0277-786X

ISSN: 1996-756X (electronic)

ISBN: 9781510647374

ISBN: 9781510647381 (electronic)

Published by

SPIE

P.O. Box 10, Bellingham, Washington 98227-0010 USA

Telephone +1 3606763290 (Pacific Time)

SPIE.org

Copyright (C) 2021 Society of Photo-Optical Instrumentation Engineers (SPIE).

Copying of material in this book for internal or personal use, or for the internal or personal use of specific clients, beyond the fair use provisions granted by the U.S. Copyright Law is authorized by SPIE subject to payment of fees. To obtain permission to use and share articles in this volume, visit Copyright Clearance Center at copyright.com. Other copying for republication, resale, advertising or promotion, or any form of systematic or multiple reproduction of any material in this book is prohibited except with permission in writing from the publisher.

Printed in the United States of America by Curran Associates, Inc., under license from SPIE.

Publication of record for individual papers is online in the SPIE Digital Library.

\section{SP|E. DIGITAL}

Paper Numbering: A unique citation identifier (CID) number is assigned to each article in the Proceedings of SPIE at the time of publication. Utilization of CIDs allows articles to be fully citable as soon as they are published online, and connects the same identifier to all online and print versions of the publication. SPIE uses a seven-digit CID article numbering system structured as follows:

- The first five digits correspond to the SPIE volume number.

- The last two digits indicate publication order within the volume using a Base 36 numbering system employing both numerals and letters. These two-number sets start with 00, 01, 02, 03, 04, 05, 06, 07, 08, 09, 0A, OB ... 0Z, followed by 10-1Z, 20-2Z, etc. The CID Number appears on each page of the manuscript. 


\section{Contents}

SESSION 1 NEURAL NETWORK AND ARTIFICIAL INTELLIGENCE ALGORITHM APPLICATION

1193302 A new item recommendation algorithm based on convolutional neural network [11933-78]

1193303 A multi-gene genetic algorithm for the Flappy Bird game based on neural network [1 1933-66]

1193304 Prediction and control of carbon emissions of electric vehicles based on BP neural network under carbon neutral background [11933-110]

$1193305 \quad$ Rolling bearing fault diagnosis based on continuous wavelet transform and transfer convolutional neural network [11933-82]

1193306 Research on risk prediction techniques of multi-sensing pyrolytic particle electrical fire in heritage buildings based on BP neural network [11933-56]

1193307 Channel quality evaluation based on Elman neural network [11933-47]

1193308 Evaluation of scientific research capability based on neural network [11933-108]

1193309 Research on enhancement algorithm for small-scale focus-spot detection [1 1933-7]

11933 OA Improved Dijkstra algorithm based on a new storage method [1 1933-97]

11933 OB Research on Chinese classification based on TF-IDF [1 1933-100]

11933 OD Network link prediction based on machine learning methods [11933-105]

11933 OE Research on complex path optimization based on data mining [11933-51]

11933 OF A design of command and control system based on neural network decision-making support algorithm [1 1933-52]

11933 OG Urban PM2.5 prediction based on temporal convolution network [1 1933-54]

$11933 \mathrm{OH} \quad$ Research on the prediction of suspect at the airport based on big data [11933-63]

11933 Ol Short-term demand forecasting of shared bicycles based on long short-term memory neural network and climate characteristics [11933-31]

11933 OJ Humor prediction with bi-directional long-short term memory [1 1933-75] 
11933 OK A hierarchical reinforcement learning method on multi UCAV air combat [1 1933-89]

$11933 \mathrm{OL} \quad$ Comparative study on deep learning models in humor detection [1 1933-71]

11933 OM The research of case retrieval system based on deep learning [11933-80]

11933 ON Research on abnormal network traffic detection based on 1D-CNN [1 1933-74]

1193300 Research on higher vocational education training reform based on BP neural network [11933-114]

11933 OP Research on judgment system of legal cases based on neural network [11933-83]

$119330 Q \quad$ HIMA-Net: humor prediction by self-attention based on key information related to humor [1 1933-73]

11933 OR Research on development model of weapon equipment construction based on system dynamics [1 1933-28]

11933 OS AHP and BP neural network-based evaluation model of higher vocational PBL english learning [1 1933-57]

11933 OT A deep learning training method of water identification based on the Third National Land Survey data [11933-41]

11933 OU Digital media information sharing platform in Internet Era [1 1933-116]

11933 OV Research on the attack strategy to reduce network effectiveness based on weighted topological separation ratio [1 1933-90]

11933 OW Traffic accident duration prediction based on natural language processing and a hybrid neural network architecture [11933-32]

\section{SESSION 2 SIGNAL IMAGE PROCESSING AND INFRARED REMOTE SENSING TECHNOLOGY}

11933 OX Remote sensing images target detection based on deep learning [11933-99]

11933 OY Design and implementation of full-body motion capture system based on multi-sensor fusion [11933-68]

$11933 \mathrm{OZ} \quad$ Numerical simulation of laser-EMAT testing depth of surface crack technology [11933-48]

1193310 Optical fiber Fabry-Perot cavity interference magnetic field sensor [11933-3]

1193311 Research on voiceprint recognition based on depth learning [11933-93] 
1193312 Symmetric multiplexing $\mathbf{2 \times 2}$ guideway optical switch based on phase change material [11933-10]

1193313 A single-frame and multi-frame based method for non-uniformity correction in uncooled infrared camera [11933-87]

1193314 Semantic segmentation of remote sensing images based on deep learning methods [11933-46]

1193315 Flow count synchronous SDN address hopping technology based on DH-RSA negotiation [11933-37]

1193316 Research on 3D reconstruction of human face based on single image [1 1933-61]

1193317 A new method for swallowing detection with binocular vision during radiotherapy [1 1933-67]

1193319 Recognition of radar emitter signal images using encoding signal methods [11933-59]

11933 1A Ship path follow based on active disturbance rejection control [11933-58]

11933 1B Nonlinear regime of laser-induced acoustic in the liquid [1 1933-38]

11933 1C Visual detection system of powder mixing equipment based on PLC [11933-111]

11933 ID Identification of faulty station area line loss based on the fusion of cross attention and deep learning algorithm [1 1933-88]

$11933 \mathrm{IE} \quad$ Research on the application of machine learning in the field of speech recognition and path planning [1 1933-113]

$119331 \mathrm{~F} \quad$ A photoelectric payload for visual self-inspection of planetary rovers [11933-19]

$119331 \mathrm{G}$ Optimal grazing angle acquisition method for traffic arteries communication signal coverage based on power lobe rotation [11933-60]

$119331 \mathrm{H} \quad$ An acoustic study on the whispery voice [11933-98]

$1193311 \quad$ Innovative research plane figure applied computer graphics image processing technology Zodiac style of woodblock New Year pictures [1 1933-55]

$119331 \mathrm{~K} \quad$ Practice of digital restoration in paleontology research and publicity [11933-35]

\section{SESSION $3 \quad$ ELECTRONIC COMMUNICATION ENGINEERING AND RADAR POSITIONING MONITORING}

$119331 \mathrm{~L} \quad$ Optimization target variable ultraviolet optical communication network fault tolerant topology control method [11933-20] 
11933 IM 3D deployment algorithm for UAV base station load capacity enhancement [11933-1]

$119331 \mathrm{~N} \quad$ Ultra-wideband multi-beam forming of the synthesized RF system based on true-time-delay technique [1 1933-9]

$1193310 \quad$ Wideband millimeter-wave antenna array for the 5G communication based on ME dipole [11933-2]

11933 1P Analysis of single event upset on certain type of calibration satellite and research on the correlation characteristics [11933-91]

$119331 Q \quad$ A target detection algorithm with local space embedded attention [1 1933-102]

11933 IR Optimal routing method for computer communication network based on Tabu search [11933-115]

11933 is A deep learning method for LiDAR bathymetry waveforms processing [1 1933-45]

$119331 \mathrm{R} \quad$ Radar emitter recognition based on CNN and LSTM [1 1933-62]

$119331 \mathrm{U}$ UAV formation control based on combining consensus control and artificial potential field [11933-104]

11933 IV Design of IEEE 802.1AS time synchronization system based on FPGA [1 1933-4]

11933 IW Wireless UV light UAV inter-aircraft avoidance algorithm based on target trajectory prediction [11933-18]

$119331 \mathrm{X} \quad$ An optimal algorithm for infrared cooperative positioning [1 1933-16]

$119331 Y$ Time-frequency domain pattern analysis of Tai Chi 12 GONG FA based on skeleton key points detection [11933-50]

$1193312 \quad$ Holographic communication technology [11933-43]

1193320 An improved approach for iterative nodes localization by using artificial bee colony [11933-109]

$1193321 \quad$ Robot path planning based on external parameter calibration and parameter fusion [11933-112]

1193322 Research on communication and positioning technology of intelligent operation and maintenance system for transmission line [1 1933-64]

1193323 Task scheduling algorithm based on backtracking strategy for phased array radar [11933-77]

$1193324 \quad$ Research on multimedia digital platform based on ergonomics [11933-29]

1193325 Through the bamboo forest: application of UAV in a Linpan development project [11933-30] 
1193326 The design and measurement of a multi-purpose performance concert hall with adjustable reverberation [1 1933-33]

1193327 Laser fabrication of stretchable graphene supercapacitors [1 1933-26]

$1193328 \quad$ F-PEAl induced performance improvement for perovskite solar cells [11933-22]

1193329 A design scheme of plug-in key intelligent lock with unique identity authentication ID [11933-14]

11933 2A Modeling and analysis of vibration characteristics of all fiber current sensor [1 1933-24]

11933 2B Research on ultra-high speed laser cladding process of corrosion resistant layer of tungsten rod for molten salt electrolysis [1 1933-17]

11933 2C An LSTM-based model for evaluation of the risk of ground collapse in coal mining area [11933-36]

11933 2D A streaming data prediction method based on long short-term memory model and grey model [11933-103]

$119332 \mathrm{E} \quad$ BERT-based regression model for micro-edit humor classification task [11933-69]

$119332 F \quad$ Design of a single channel Doppler direction finding system [11933-65]

$119332 \mathrm{G}$ Application of improved adaptive genetic algorithm in energy consumption optimization of electric refrigerated vehicles [11933-92]

$119332 \mathrm{H} \quad$ Improvement of cyclic stability of $\mathrm{V}_{\mathbf{2}} \mathrm{O}_{5}$ electrochromic films via polymer tetrabutylammonium perchlorate [11933-21]

$1193321 \quad$ Unimorph deformable mirror for oblique incidence applications [11933-11]

$119332 \mathrm{~J} \quad$ An automatic trading system based on the transaction model that selects advantageous trading opportunities and increases positions [1 1933-79]

11933 2K The true single-port compartor in multiple channel SAR ADC [1 1933-86]

11933 2L Design of dry-type transformer temperature controller based on MCU [1 1933-49]

$119332 \mathrm{M}$ Research on the combined model of corporate failure prediction [11933-40]

$119332 \mathrm{~N}$ Method for predicting behavior of substation workers based on generative confrontation network [1 1933-72] 
1193320 Safe distance monitoring method of substation based on machine vision [11933-107]

$119332 \mathrm{P}$ The construction and application of a quantitative trading system based on a trading model that repeatedly trades at the same price [11933-81]

$119332 \mathrm{R}$ Research on edge service random access technology for continuous guarantee [11933-96]

$119332 R \quad$ Combinatorial selective redundant transmissions of real-time video stream through multiinterface wireless terminals [1 1933-84] 